\section{Environmental Toxicants: Human Exposures and Their Health Effects, 3rd Edition}

by Morton Lippmann (ed): Wiley, Hoboken, NJ, USA, 2009, pp 1167 + xix, ISBN: 978-0-471-79335-9.

Price: EUR 159.00, USD 195.00

I agreed to review this book because I assumed from the title that it would contain some analytical content-a book on human exposure must, I thought, surely, include some chemical analysis. If it does, it is well hidden. The book is, instead, an encyclopaedic collection of (non-occupational) levels of toxicants likely to be encountered, and toxicity data associated with these; if analysis of the toxicants had been covered in the same depth the book would have been at least twice the size. According to the book's cover, this edition has been thoroughly updated and includes new chapters on arsenic and endocrine disruptors; it also covers new developments on the effects of exposure to asbestos, carbon monoxide, diesel exhaust, dioxins, bioaerosols, mercury, radon, and ultraviolet irradiation. According to the same publicity it is written by leading environmental health scientists. Of the forty-two contributors listed, all but five work in the USA; this balance is, perhaps, apparent from the use of English in the second part of the book's title.
The book contains 30 chapters and the criteria used to arrange these, if any, are not obvious. The first is, of course, the Introduction. The next seven cover general topics (risks, their reduction, respiratory toxicology, industrial perspectives and practices, by-products from disinfection of drinking water, and food). The other 22 cover specific toxicants or groups of toxicants (volatile organic compounds, including sick-building syndrome, formaldehyde and other aldehydes, air particulate matter, arsenic, asbestos and other fibres, benzene, carbon monoxide, chromium, diesel exhaust, dioxins, endocrine disruptors, secondhand smoke, lead, mercury, oxides of nitrogen, ozone, pesticides, oxides of sulphur (including acids and acid salts), microwaves and electromagnetic fields, man-made radiation and radioactivity, noise, radon, and ultraviolet radiation) in, very approximately, alphabetical order. All the topics are covered in great depth and most of the chapters, especially those on specific toxicants, include comprehensive reference lists, including many references to work published in the last 20 years. The book makes good use of figures and tables, and finishes with a four-page index, which seems somewhat scanty given the size of the book.

Besides being experts in their subjects, the authors very clearly enjoy their work. Most of the book reflects this and is a delight to read. For a book with such a wide range of topics there will, inevitably, be variation in their treatment-obvi- ously the chapter on food, with many thousands of potential contaminants, is written from a perspective completely different from that on, for example, benzene (both make extremely enjoyable reading). This does not, to my mind, detract from the quality. The book is mostly well written and edited. I take issue with excessive use of 'As' rather than 'arsenic' in the chapter on this element, especially at the beginning of a sentence-I lost count of the number of times I had to re-read a sentence to grasp what I was reading. And, when all the main headings are in upper case, do the publishers really believe the heading 'As essentiality' looks better than 'Arsenic essentiality'? Oh dear. I can happily report such dreadful crimes have been avoided in the chapters on lead and chromium.

Despite these moans this is an excellent and well-produced guide to the subject. In the Introduction the book is described as a source of state-of-the-art knowledge for public health authorities, physicians, and industrial managers which can also be used in graduate and post-graduate training and by research workers including toxicologists, clinicians, and epidemiologists. I cannot fault this assessment - the depth of coverage is awesome. It is also an interesting text for browsing by anyone interested in the topics covered. I will certainly be dipping into it from time to time.

I.W. Davies 